\title{
Novel herbal medicine LA16001 ameliorates cisplatin-induced anorexia
}

\author{
SANG-MI WOO ${ }^{1}$, KANG MIN LEE ${ }^{2}$, GYU RI LEE ${ }^{2}$, JI YOUN PARK ${ }^{2}$, HEE JAE LEE ${ }^{2}$, HYO-JUNG BAHN ${ }^{2}$, \\ HYUN SEOK YOON ${ }^{2}$, JEM YUNG KIM ${ }^{2}$, YOUNG CHEOL SHIN ${ }^{3}$, SUNG-GOOK CHO ${ }^{4}$ and SEONG-GYU KO ${ }^{3}$ \\ Departments of ${ }^{1}$ Cancer Preventive Material Development and ${ }^{2}$ Science in Korean Medicine, Graduate School; \\ ${ }^{3}$ Department of Preventive Medicine, College of Korean Medicine, Kyung Hee University, Seoul 02447; ${ }^{4}$ Department of \\ Biotechnology, Korea National University of Transportation, Jeungpyeong, Chungbuk 368-701, Republic of Korea
}

Received December 20, 2016; Accepted March 14, 2017

DOI: $10.3892 / \mathrm{mmr} .2017 .8176$

\begin{abstract}
Chemotherapy frequently causes anorexia in cancer patients, which has been associated with poor disease prognosis. Several therapeutic strategies for the treatment of chemotherapy-induced anorexia are available; however, their adverse effects limit their clinical use. Herbal medicines have a long history of use for the treatment of various diseases, including cancer, and recent research has demonstrated their safety and efficacy. In the present study, combinations of herbal medicines were designed based on traditional Korean medicine, and their effects were investigated on chemotherapy-induced anorexia. Herbal mixtures were extracted, composed of Atractylodes japonica, Angelica gigas, Astragalus membranaceus, Lonicera japonica Thunb., Taraxacum platycarpum H. Dahlstedt and Prunella vulgaris var. asiatica (Nakai) Hara. The mixtures were termed LCBP-Anocure-16001-3 (LA16001, LA16002, LA16003). A cisplatin-induced anorexic mouse model was used to evaluate the putative effects of the extracts on chemotherapy-induced anorexia. Treatment with LA16001 was revealed to prevent body weight loss, and all three extracts were demonstrated to improve food intake. When the molecular mechanisms underlying the orexigenic effects of LA16001 were investigated, altered expression levels of ghrelin, leptin and interleukin-6 were revealed. Furthermore, LA16001 was reported to induce phosphorylation of Janus kinase 1 and signal transducer and
\end{abstract}

Correspondence to: Ms. Sang-Mi Woo, Department of Cancer Preventive Material Development, Graduate School, Kyung Hee University, 26 Kyungheedae-ro, Seoul 02447, Republic of Korea

E-mail: taoya@hanmail.net

Professor Seong-Gyu Ko, Department of Preventive Medicine, College of Korean Medicine, Kyung Hee University, 26 Kyungheedae-ro, Seoul 02447, Republic of Korea

E-mail: epiko@khu.ac.kr

Key words: chemotherapy-induced anorexia, cisplatin, LA16001, herbal medicines activator of transcription 3. In addition, LA16001 administration increased the number of white blood cells and neutrophils. These results suggested that the herbal formula LA16001 may be able to prevent chemotherapy-induced anorexia and may have potential as a novel therapeutic strategy for the adjuvant treatment of patients with cancer.

\section{Introduction}

Chemotherapeutic agents used for the treatment of patients with cancer have been associated with serious adverse effects, including tiredness, nephrotoxicity, anemia, leukopenia, nausea, vomiting and loss of appetite (1-3). Vomiting and appetite loss in patients with cancer have been linked to the development of anorexia (4-6). Numerous patients with cancer who suffer from chemotherapy-induced anorexia have been reported to struggle with the continuation of treatment, thus resulting in poor disease prognosis and impaired quality of life $(6,7)$. Megestrol acetate (MGA) is a steroidal drug that is currently used as an appetite stimulant (8-11), as it can increase appetite and promote weight gain in patients with chemotherapy-induced anorexia $(12,13)$. However, the use of MGA has been associated with numerous adverse effects, including excessive weight gain, fluctuations in appetite and gastrointestinal complications $(14,15)$. Our previous study demonstrated that the traditional Korean medicine sip-jeon-dae-bo-tang (SJDBT) was more effective in improving food intake in cisplatin-induced and tumor-induced anorexic mouse models compared with MGA $(16,17)$. Furthermore, the traditional Kampō medicine rikkunshito has been demonstrated to ameliorate cisplatin-induced anorexia in rats and humans $(18,19)$. These findings suggested that herbal formulas used in traditional Eastern medicine may have potential as alternative therapeutic strategies for the prevention and treatment of chemotherapy-associated anorexia in patients with cancer.

A herbal formula termed LCBP-Anocure-16001 (LA16001) has been designed based on traditional Korean medicine and SJDBT, and its effects have been investigated on chemotherapy-induced anorexia (20). The formula consists of a combination of herbal extracts from Atractylodes japonica (AJ), Angelica gigas (AG), Astragalus membranaceus (AM), 
which are included in SJDBT, with extracts from Lonicera japonica Thunb. (LJ), Taraxacum platycarpum $\mathrm{H}$. Dahlstedt (TP), and Prunella vulgaris var. asiatica (Nakai) Hara (PV), at a 1:1:1:1:1:1 ratio. AJ, AG and AM have been used in traditional Korean medicine for the treatment of anorexia, anemia, fatigue, general weakness, and for immunopotentiation (21-26). In Korean tradition, LJ and TP have been reported to alleviate drug-induced toxicity and fever, and exert anti-inflammatory and diuretic effects $(27,28)$, whereas PV has traditionally been used for its antiviral and antibacterial properties, and for the treatment of indigestion $(29,30)$.

In the present study, a cisplatin-induced anorexic mouse model was employed to investigate the effects of LA16001 on appetite. LA16001 was demonstrated to increase food intake and body weight, and its effects were more potent compared with SJDBT and MGA. The molecular mechanisms underlying its effects appeared to involve altering the levels of ghrelin, leptin and interleukin (IL)-6, potentially via regulation of the Janus kinase (JAK) 1/signal transducer and activator of transcription (STAT) 3 pathway. In addition, LA16001 was demonstrated to prevent chemotherapy-associated leukopenia and neutropenia. These results suggested that LA16001 may have potential as an alternative herbal therapeutic strategy for the treatment of patients with chemotherapy-induced anorexia.

\section{Materials and methods}

Herbal extracts and reagents. The herbal formulas were composed of extracts from AJ, AG, AM, LJ, TP and PV, at $\mathrm{w} / \mathrm{w}$ ratios of $1: 1: 1: 1: 1: 1,1: 1: 1: 2: 2: 2$ or $2: 2: 2: 1: 1: 1$. The herbal formulas were termed LCBP-Anocure-16001, 16002 and 16003 (LA16001, LA16002, LA16003), respectively. Herbal medicines were obtained from Kyung Hee Herb Pharm (Wonju,) and Omniherb (Seoul, Korea). LA16001 was composed of $40 \mathrm{~g}$ each of AJ, AG, AM, LJ, TP and PV; LA16002 was composed of $25 \mathrm{~g}$ each of AJ, AG and AM and $50 \mathrm{~g}$ each of LJ, TP and PV; LA16003 was composed of $50 \mathrm{~g}$ each of AJ, AG and AM and $25 \mathrm{~g}$ each of LJ, TP and PV. The ingredients were placed in 15 -fold volume of distilled water and boiled at $\sim 100^{\circ} \mathrm{C}$ for $3 \mathrm{~h}$. The extracts were filtered using $75 \mu \mathrm{m}$ microfilters. The filtered residues were placed in a 15 -fold volume of distilled water, boiled at $\sim 100^{\circ} \mathrm{C}$ for $3 \mathrm{~h}$ and refiltered through $75-\mu \mathrm{m}$ microfilters. The extracted liquid was concentrated under low pressure at $60^{\circ} \mathrm{C}$. Finally, $81.8 \mathrm{~g}$ (LA16001), $84 \mathrm{~g}$ (LA16002) and $93.3 \mathrm{~g}$ (LA16003) dried extract was obtained; the yields were $34.08,37.33$ and $41.47 \%$, respectively. The extracts were prepared according to the Good Manufacturing Practice guidelines (31,32). SJDBT was obtained from Hanpoong Pharm \& Foods Co., Ltd. (Jeonju, Korea) and was prepared as previously described (16). Cisplatin (8 mg/kg) (Sigma-Aldrich; Merck KGaA, Darmstadt, Germany) was dissolved in distilled water.

Animal study. A total of 98 male BALB/c mice (age, 6 weeks) were purchased from Orient Bio Inc. (Seongnam, Korea). Mice ( $n=4 /$ group) were randomly assigned to the following groups: Normal, control, cisplatin, LA16001, LA16002, LA16003, SJDBT, MGA (Sigma-Aldrich; Merck $\mathrm{KGaA}), \mathrm{AJ}, \mathrm{AG}, \mathrm{AP}, \mathrm{LJ}, \mathrm{TP}$ and PV, and were maintained at $23 \pm 3^{\circ} \mathrm{C}$ (humidity, $55 \pm 15 \%$ ), under a 12 -h light/dark cycle.
Access to food and water was ad libitum, apart from during the experimental period. All groups (except the normal group) were fasted for $24 \mathrm{~h}$ prior to the start of the experiment (the normal group was used as a control for starvation). The control group did not receive any drug treatment, only starvation; this group was used as a control for the cisplatin group. All groups (except the normal and control groups) were induced to become anorexic through administration of cisplatin. Therefore, the cisplatin group was used as a control for the drug treatments. The drug was administered at the concentration of $1,000 \mathrm{mg} / \mathrm{kg}$ on days $1-3$. After $24 \mathrm{~h}, 8 \mathrm{mg} / \mathrm{kg}$ cisplatin was intraperitoneally injected into the mice. During fasting, water was continuously provided and food was provided following the oral administration of drugs. Food intake and body weight were measured daily throughout the duration of the study (Fig. 1A). An equal amount of food was given at the same time each day and mice were weighed the following day. All mice were sacrificed at the time labeled 'Sac' in the animal study design presented in Fig. 1A. Blood and adipose tissue, stomach, and hypothalamus were obtained from the sacrificed mice.

The present study was approved by the Animal Ethics Committee of Kyung Hee University [approval no. KHUASP (SE)-016-100].

ELISA and blood analysis. Samples from stomach, fat and hypothalamic tissue were isolated from mice sacrificed $4 \mathrm{~h}$ subsequent to the administration of cisplatin ( $n=4$ mice/group), and lysed with radioimmunoprecipitation assay lysis buffer (Biosesang, Inc., Seongnam, Korea). Lysates were centrifuged at $196 \mathrm{x} \mathrm{g}$ for $20 \mathrm{~min}$ at room temperature, and supernatants were collected and used for the assessment of target proteins using ELISA. The levels of ghrelin (cat. no. EZRGRA-90K; EMD Millipore, Billerica, MA, USA), leptin (cat. no. DY498; R\&D Systems, Inc., Minneapolis, MN, USA) and IL-6 (cat. no. 555240; BD Biosciences, San Jose, CA, USA) were measured using ELISA kits according to the manufacturer's protocol. The blood of the mice sacrificed 3 days subsequent to the administration of cisplatin was used. Control group and cisplatin group, LA16001 group mice were used, 4 mice/group. Exsanguination was performed, and whole blood was analyzed using the HEMAVET ${ }^{\circledR} 950$ hematology system (Drew Scientific Inc., Miami Lakes, FL, USA). SigmaPlot, version 2001 (Systat Software, Inc., San Jose, CA, USA) was used for analysis of the blood data. To anesthetize, $400 \mu \mathrm{l} /$ mouse $1.2 \%$ avertin solution was intraperitoneally injected [1.2\% avertin solution, 0.5 g 2,2,2-tribromoethanol powder (Sigma-Aldrich; Merck $\mathrm{KGaA}$ ) dissolved in $1 \mathrm{ml}$ 2-methyl-2-butanol (Sigma-Aldrich; Merck $\mathrm{KGaA}$ ) at $55^{\circ} \mathrm{C}$, and $\left.39 \mathrm{ml} \mathrm{PBS}\right]$. The avertin solution was filtered through a Nalgene $0.22-\mu \mathrm{m}$ filter (Thermo Fisher Scientific, Inc., Waltham, MA, USA).

Western blot analysis. Adipose tissue was isolated from mice. To obtain protein, the adipose tissue was lysed using radioimmunoprecipitation assay buffer (Biosesang, Inc.) and was centrifuged at $24,562 \mathrm{x}$ g at $4^{\circ} \mathrm{C}$ for $20 \mathrm{~min}$. Protein concentration was measured using a Bradford assay. Equal amounts of extracted protein samples $(20 \mu \mathrm{g})$ were separated by $8 \%$ SDS-PAGE and transferred onto polyvinylidene difluoride membranes (GE Healthcare Life 

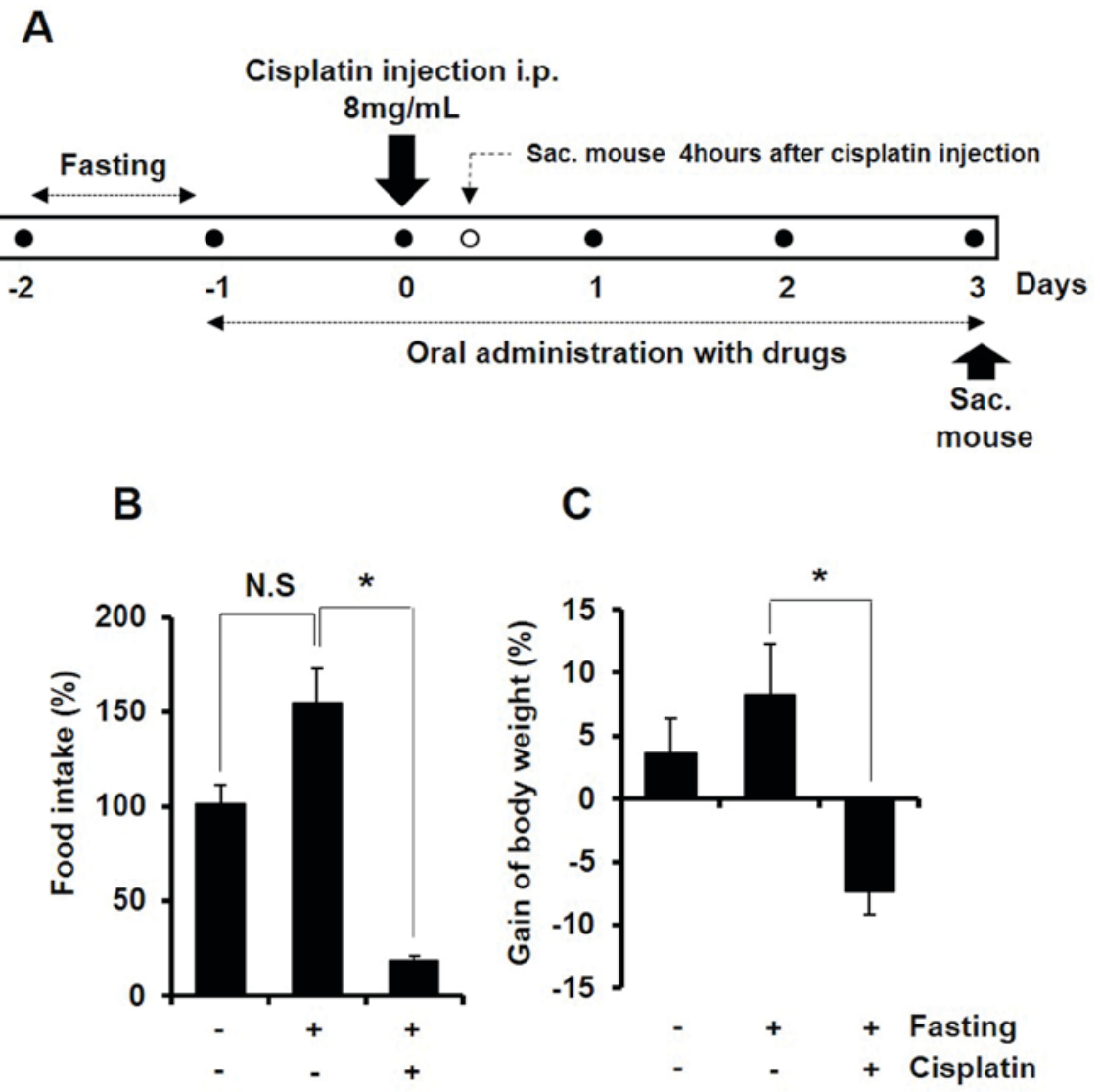

Figure 1. Treatment with cisplatin decreases food intake in BALB/c mice. (A) Time frame of the in vivo study. All mice (except the normal group) fasted for $24 \mathrm{~h}$ and all mice (except the normal and control groups) were intraperitoneally administered with $8 \mathrm{mg} / \mathrm{kg}$ cisplatin. The groups were administered orally LA16001, LA16002, LA16003, SJDBT, MAG, AP, AG, AJ, TP, LJ and PV for three days, respectively. Mice were sacrificed 4 h or 3 days post-injection and tissue samples were collected for further analysis. (B) Food intake and (C) body weight gain were monitored daily throughout the duration of the study. Data are presented as the mean \pm standard deviation. ${ }^{*} \mathrm{P}<0.05$. NS, not significant; Sac., sacrifice.

Sciences, Chalfont, UK). Membranes were blocked in $1 \%$ bovine serum albumin (Sigma-Aldrich; Merck KGaA) and $2 \%$ skimmed milk for $1 \mathrm{~h}$ at room temperature. Membranes were then incubated at $4^{\circ} \mathrm{C}$ overnight with the following primary antibodies: Anti-phosphorylated (p)-JAK1 (1:1,000; cat no. 3331; Cell Signaling Technology, Inc., Danvers, MA, USA), anti-p-STAT3 (1:1,000; cat no. 9131; Cell Signaling Technology, Inc.) and anti- $\alpha$-tubulin (1:10,000; cat no. T-5168; Sigma-Aldrich; Merck KGaA). Subsequently, membranes were incubated with horseradish peroxidase-conjugated secondary antibody (1:2,000 in 1x PBS with $0.05 \%$ Tween-20; cat. no. 5450-0010; KPL, Inc., Gaithersburg, MD, USA) for $1 \mathrm{~h}$ at room temperature. Protein bands were visualized using Enhanced Chemiluminescence kit solution (DoGen, Seoul, Korea) and quantified using ImageJ software version $1.49 \mathrm{v}$ (National Institutes of Health, Bethesda, MD, USA) and normalized to $\alpha$-tubulin.

Statistical analysis. The data are expressed as the mean \pm standard deviation and experiments were performed on 4 mice/ group. The statistical significance of the differences between groups was assessed using Student's t-test. Statistical analysis was performed using Microsoft Excel 2013 (Microsoft Corporation, Redmond, WA, USA). $\mathrm{P}<0.05$ was considered to indicate a statistically significant difference. One-way analysis of variance was additionally performed with post hoc test (Tukey), using SPSS software (version 23; IBM Corp., Armonk, NY, USA).

\section{Results}

LA16001-3 increases food intake in cisplatin-induced anorexic mice. Mice were fasted for $24 \mathrm{~h}$ and intraperitoneally injected with $8 \mathrm{mg} / \mathrm{kg}$ cisplatin. Experimental drugs were orally administrated $24 \mathrm{~h}$ before cisplatin injection. To investigate the effects of the experimental drugs on food intake and body weight, mice were maintained for 3 days following the injection of cisplatin (Fig. 1A). The results of the present study demonstrated that following cisplatin administration, food intake and body weight decreased (Figs. 1B and C, respectively). Notably, LA16001, LA16002, LA16003, SJDBT and MGA alleviated cisplatin-induced loss of appetite (Fig. 2A), and LA16001 and MGA significantly reversed decreases in body weight (Fig. 2B). LA16001 appeared to have more potent orexigenic effects on food intake, compared with all other treatment groups (Fig. 2A). In addition, all treatment groups demonstrated significantly reversed cisplatin-induced loss of appetite, with LA16001 exerting the most pronounced effect (Fig. 3A). Furthermore, LA16001, AP, AG and TP treatment significantly reversed loss of body weight in experimental mice, again with LA16001 being the most effective (Fig. 3B). These results 
A

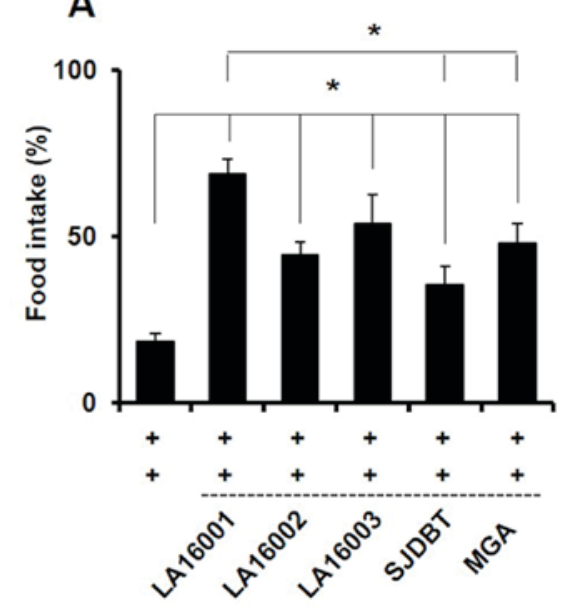

B

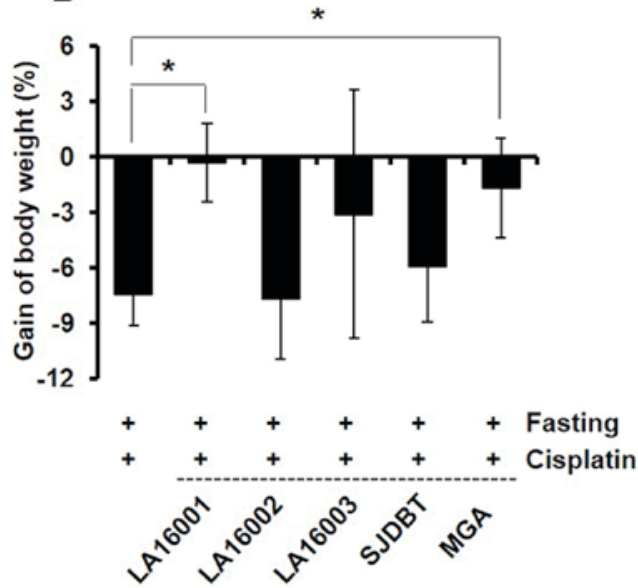

Figure 2. Treatment with LA16001-3 increases food intake and body weight in cisplatin-induced anorexic mice. Mice were fasted for $24 \mathrm{~h}$ and orally administered with LA16001, LA16002 or LA16003 (1,000 mg/kg), SJDBT $(678.4 \mathrm{mg} / \mathrm{kg})$ or MGA (100 mg/kg). After $24 \mathrm{~h}$, mice received an intraperitoneal cisplatin $(8 \mathrm{mg} / \mathrm{kg}$ ) injection. (A) Food intake and (B) body weight gain were monitored daily throughout the duration of the study. Data are presented as the mean \pm standard deviation. "P<0.05. LA16001-3, LCBP-Anocure 16001-3; SJDBT, sip-jeon-dae-bo-tang; MGA, megestrol acetate.
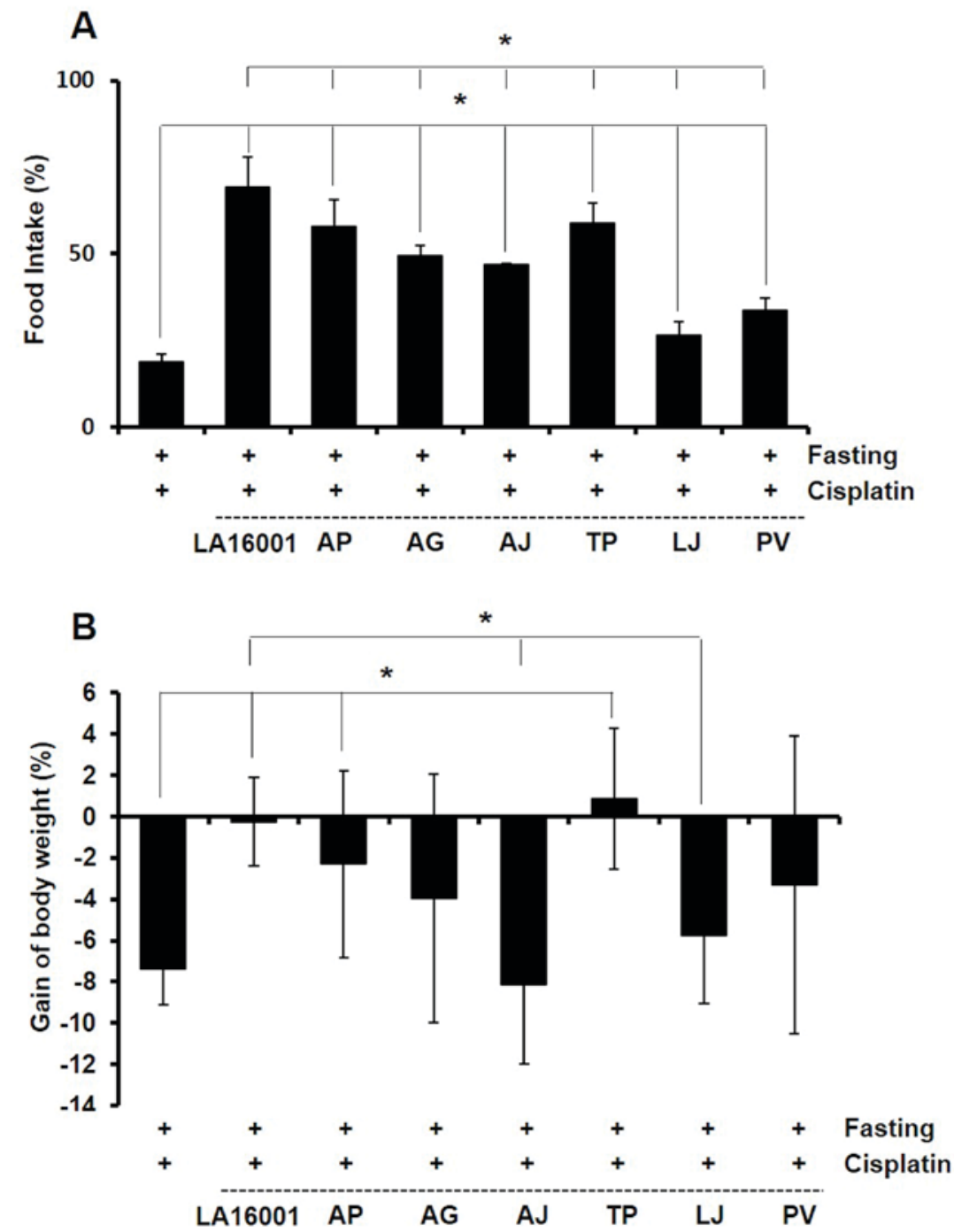

Figure 3. Effects of LA16001 on food intake and body weight in cisplatin-induced anorexic mice. Mice were fasted for $24 \mathrm{~h}$ and orally administered with LA16001, AJ, AG, AP, LJ, TP and PV (1,000 mg/kg). After $24 \mathrm{~h}$, mice received an intraperitoneal cisplatin (8 mg $/ \mathrm{kg})$ injection. (A) Food intake and (B) body weight gain were monitored daily throughout the duration of the study. Data are presented as the mean \pm standard deviation. ${ }^{*} \mathrm{P}<0.05$. LA16001, LCBP-Anocure 16001; AJ, Atractylodes japonica; AG, Angelica gigas; AM, Astragalus membranaceus; LJ, Lonicera japonica Thunb.; TP, Taraxacum platycarpum H. Dahlstedt; PV, Prunella vulgaris var. asiatica (Nakai) Hara. 

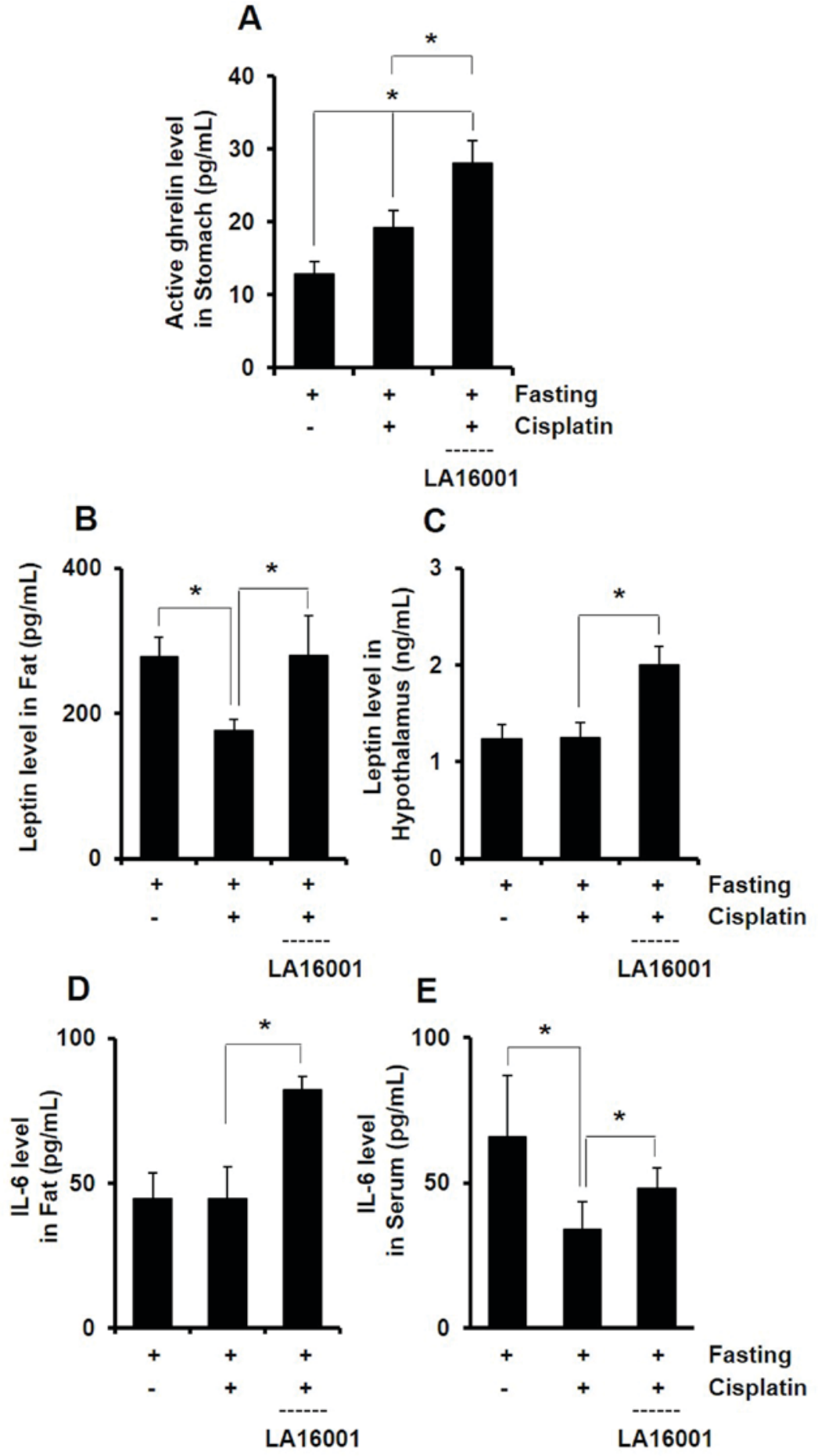

Figure 4. Treatment with LA16001 alteres the levels of the appetite-associated hormones active ghrelin and leptin, and of IL-6 in cisplatin-induced anorexic mice. Mice were fasted for $24 \mathrm{~h}$ and orally administered with LA16001 (1,000 mg/kg). After $24 \mathrm{~h}$, mice received an intraperitoneal cisplatin $(8 \mathrm{mg} / \mathrm{kg})$ injection. (A) Active ghrelin (ghrelin which performs appetite stimulatory function) levels were measured in stomach tissue samples. Leptin levels were measured in (B) fat tissue or (C) serum samples. IL-6 levels were measured in (D) fat tissue or (E) serum samples using ELISA. Data are presented as the mean \pm standard deviation. ${ }^{*} \mathrm{P}<0.05$. LA16001, LCBP-Anocure 16001; IL, interleukin.

suggested that LA16001 may be able to counteract cisplatin-induced anorexia in vivo.

LA16001 increases the levels of appetite-associated hormones in cisplatin-treated mice. A total of $4 \mathrm{~h}$ post-cisplatin injection, the hormone levels of ghrelin, leptin and IL-6 were assessed in mouse tissue and serum samples. Mice in the cisplatin and LA16001 groups exhibited increased ghrelin levels in stomach tissue samples compared with mice in the fasting control group (Fig. 4A). Cisplatin was demonstrated to reduce leptin levels in fat and hypothalamic tissue, whereas LA16001 appeared to counteract this effect (Figs. 4B and C). IL-6 levels were assessed in serum and fat tissue samples. IL-6 levels in fat tissue were not altered following cisplatin administration; however, they were significantly decreased in serum samples. Notably, LA16001 administration was 
A

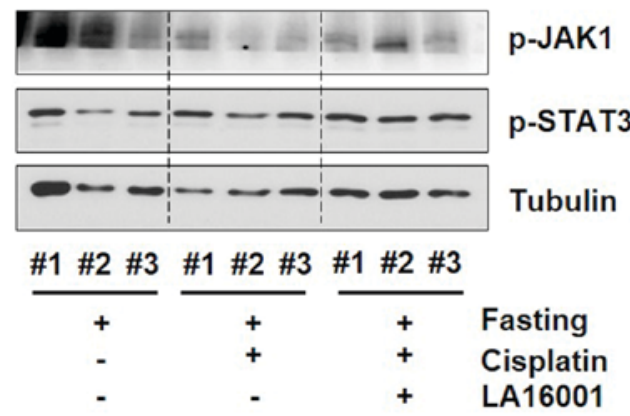

B
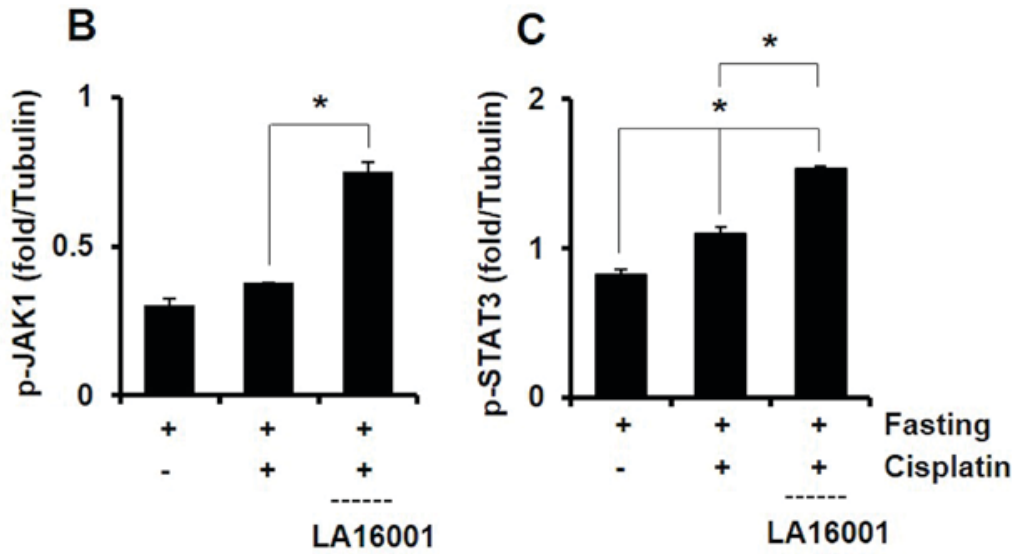

Figure 5. Treatment with LA16001 activates the JAK1/STAT3 intracellular signaling pathway in fat tissue of cisplatin-induced anorexic mice. Mice were fasted for $24 \mathrm{~h}$ and orally administered with LA16001 (1,000 mg/kg). Following $24 \mathrm{~h}$, mice received an intraperitoneal cisplatin $(8 \mathrm{mg} / \mathrm{kg})$ injection. Fat tissue samples were isolated from 3 different mice belonging to the same treatment group. (A) Representative western blot images of expression of p-JAK1 and p-STAT3 protein expression levels. Treatment with LA16001 upregulated the protein expression levels of (B) p-JAK1 and (C) p-STAT3 in mouse fat tissue. Data are presented as the mean \pm standard deviation. "P<0.05. LA16001, LCBP-Anocure 16001; JAK, Janus kinase; STAT, signal transducer and activator of transcription; p-, phosphorylated.

A

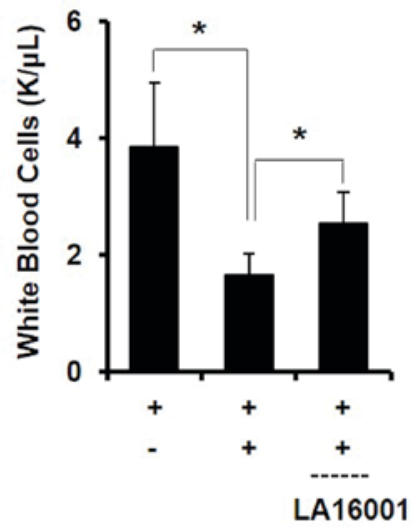

B

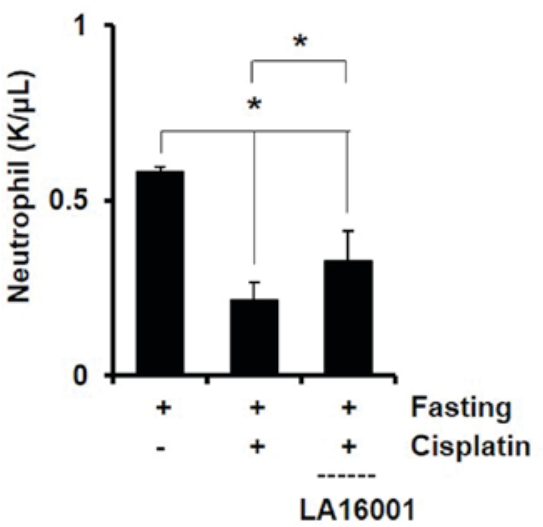

Figure 6. LA16001 prevents immunosuppression in cisplatin-induced anorexic mice. Mice were fasted for $24 \mathrm{~h}$ and orally administered with LA16001 $(1,000 \mathrm{mg} / \mathrm{kg})$. Following $24 \mathrm{~h}$, mice received an intraperitoneal cisplatin $(8 \mathrm{mg} / \mathrm{kg})$ injection. White blood cell and neutrophil counts were performed 3 days following cisplatin administration in whole blood samples. LA16001 counteracted the suppressive effects of cisplatin on (A) white blood cell and (B) neutrophil numbers. Data are presented as the mean \pm standard deviation. ${ }^{*} \mathrm{P}<0.05$. LA16001, LCBP-Anocure 16001.

demonstrated to significantly increase fat tissue and serum IL-6 levels (Figs. 4D and E). These results indicated that LA16001 administration increased the levels of ghrelin, leptin and IL-6 in cisplatin-treated mice.
LA16001 activates the JAK1/STAT3 signaling pathway in fat tissue. A total of $4 \mathrm{~h}$ post-cisplatin injection, the phosphorylation status of JAK1 and STAT3 was investigated in fat tissue samples. LA16001 administration resulted in significantly 
increased protein expression levels of p-JAK1 and p-STAT3 compared with the cisplatin group (Figs. 5A and B). These results suggested that the molecular mechanisms underlying the orexigenic effects of LA16001 in cisplatin-induced anorexic mice may involve the activation of the JAK1/STAT3 intracellular signaling pathway.

LA16001 prevents immunosuppression in cisplatin-induced anorexic mice. White blood cell and neutrophil counts were performed 3 days after cisplatin administration to evaluate the effects of LA16001 on chemotherapy-induced immunosuppression. Treatment with cisplatin was demonstrated to reduce the numbers of white blood cells (Fig. 6A) and neutrophils (Fig. 6B) in mouse whole blood samples. Notably, LA16001 administration appeared to counteract the effects of cisplatin on immune cell numbers (Fig. 6). These results suggested that LA16001 may mitigate the immunosuppressive effects associated with cisplatin treatment.

\section{Discussion}

Chemotherapy induces various side effects, including anorexia. Anticancer drugs are toxic to healthy cells as they share characteristics with rapidly dividing cancer cells. The healthy cells that are primarily affected are hair follicle cells, and cells of the mouth, stomach, large intestine and the mucous membrane of the anus, which exhibit a rapid growth rate compared with other cells $(33,34)$. Anorexia is particularly induced by gastrointestinal toxicity (35). Anorexia is a frequent adverse event following cancer chemotherapy, and has been associated with poor disease prognosis and treatment discontinuation (1).

Previous studies have suggested that herbal formulas used in traditional Eastern medicine may have potential as alternative strategies for the treatment of chemotherapy-induced anorexia $(16,36,37)$. In the present study, the herbal formula LA16001 was developed, and was demonstrated to effectively counteract the development of chemotherapy-induced anorexia in mice. LA16001 prevented the loss of appetite and body weight following cisplatin administration. Ghrelin is a hormone critical for appetite regulation, and its levels have been reported to decrease following food intake (38). Leptin is a hormone functioning as an appetite suppressant, and its levels increase following feeding (39). IL-6 is a proinflammatory cytokine that has been revealed to function together with leptin to increase appetite (40). Patients with cancer with anorexia due to anticancer drugs exhibit increased ghrelin and decreased leptin (41). Leptin and IL-6 have been demonstrated to act through the regulation of the JAK1/STAT3 intracellular signaling pathway. STAT3 is involved in the food intake and glucose metabolism of leptin. Leptin was observed to function abnormally in STAT3-deficient mice $(41,42)$. In the present study, LA16001 was revealed to increase ghrelin, leptin, IL-6, p-JAK1 and p-STAT3 levels in cisplatin-treated mice, suggesting that it may mitigate cisplatin-associated appetite suppression via a mechanism involving the JAK1/STA3 signaling pathway.

Our previous study revealed that SJDBT counteracted the appetite-suppressing effects associated with chemotherapy in cisplatin-induced anorexic mice (16). Notably, SJDBT appeared to prevent cisplatin-induced anorexia more effectively compared with MGA (16). In the present study, LA16001 appeared to exert more potent effects against cisplatin-induced anorexia compared with SJDBT. The effects of LA16001 on the expression of ghrelin, leptin and IL-6 suggested that this novel herbal composition may effectively treat cisplatin-induced anorexia.

Anticancer drugs target the bone marrow cells from which blood cells are derived, thereby decreasing white blood cell count and inducing immune degradation (43-45). Immunosuppression is a frequent and serious adverse event observed in patients with cancer receiving chemotherapy (43-45). The present study assessed the effects of LA16001 on cisplatin-induced immunosuppression, through the evaluation of white blood cell and neutrophil counts in cisplatin-treated mice. The present results suggested that LA16001 may prevent immune disorders associated with chemotherapy in cisplatin-induced anorexic mice.

In conclusion, the present study revealed that the herbal mixture LA16001 ameliorated the appetite-suppressing effects of cisplatin in a chemotherapy-induced anorexic mouse model. LA16001 was demonstrated to modulate hormone and cytokine levels, potentially via activation of the JAK1/STAT3 intracellular signaling pathway. Furthermore, LA16001 counteracted the immunosuppressive effects of cisplatin, as demonstrated by an increase in immune cell numbers. The present results suggested that LA16001 may have potential as an alternative therapeutic strategy for the prevention and treatment of chemotherapy-associated anorexia in patients with cancer. Further studies are required to validate the orexigenic effects of LA16001, and to investigate the cellular and molecular mechanisms underlying its actions.

\section{Acknowledgements}

The authors would like to thank Hanpoong Pharm \& Foods Co., Ltd. (Jeonju, Korea) for providing some of the herbal extracts used in the present study. The present study was supported by the Korean Medicine R\&D project of the Ministry of Health and Welfare (grant no. B120014) and by the National Research Foundation of Korea, funded by the Korean Ministry of Science (grant no. 2007-0054931).

\section{References}

1. Yao X, Panichpisal K, Kurtzman N and Nugent K: Cisplatin nephrotoxicity: A review. Am J Med Sci 334: 115-124, 2007.

2. Coates A, Abraham S, Kaye SB, Sowerbutts T, Frewin C, Fox RM and Tattersall MH: On the receiving end-patient perception of the side-effects of cancer chemotherapy. Eur J Cancer Clin Oncol 19: 203-208, 1983.

3. Decker-Baumann C, Buhl K, Frohmüller S, von Herbay A, Dueck M and Schlag PM: Reduction of chemotherapy-induced side-effects by parenteral glutamine supplementation in patients with metastatic colorectal cancer. Eur J Cancer 35: 202-207, 1999.

4. Mantovani G, Maccio A, Bianchi A, Curreli L, Ghiani M, Santona MC and Del Giacco GS: Megestrol acetate in neoplastic anorexia/cachexia: Clinical evaluation and comparison with cytokine levels in patients with head and neck carcinoma treated with neoadjuvant chemotherapy. Int J Clin Lab Res 25: 135-141, 1995.

5. Bender CM, McDaniel RW, Murphy-Ende K, Pickett M, Rittenberg CN, Rogers MP, Schneider SM and Schwartz RN: Chemotherapy-induced nausea and vomiting. Clin J Oncol Nurs 6: 94-102, 2002. 
6. Bosnjak SM, Dimitrijevic J and Djordjevic F: Cancer and chemotherapy-induced nausea and vomiting: A focus on olanzapine. Curr Opin Support Palliat Care 10: 180-188, 2016.

7. Metri K, Bhargav H, Chowdhury P and Koka PS: Ayurveda for chemo-radiotherapy induced side effects in cancer patients. J Stem Cells 8: 115-129, 2013.

8. Aoyagi T, Terracina KP, Raza A, Matsubara H and Takabe K: Cancer cachexia, mechanism and treatment. World J Gastrointest Oncol 7: 17-29, 2015

9. Fernández-Lucas M, Díaz-Domínguez ME, Ruiz-Roso G Raoch V, Teruel-Briones JL and Quereda-Rodríguez-Navarro C: Anorexia and megestrol acetate: Treatment versus placebo controlled study. Nefrologia 34: 416-417, 2014

10. Cuvelier GD, Baker TJ, Peddie EF, Casey LM, Lambert PJ, Distefano DS, Wardle MG, Mychajlunow BA, Romanick MA, Dix DB and Wilson BA: A randomized, double-blind, placebo-controlled clinical trial of megestrol acetate as an appetite stimulant in children with weight loss due to cancer and/or cancer therapy. Pediatr Blood Cancer 61: 672-679, 2014

11. De Conno F, Martini C, Zecca E, Balzarini A, Venturino P, Groff L and Caraceni A: Megestrol acetate for anorexia in patients with far-advanced cancer: A double-blind controlled clinical trial. Eur J Cancer 34: 1705-1709, 1998.

12. Ruiz Garcia V, López-Briz E, Carbonell Sanchis R, Gonzalvez Perales JL and Bort-Marti S: Megestrol acetate for treatment of anorexia-cachexia syndrome. Cochrane Database Syst Rev 28: CD004310, 2013.

13. Sung JH, An HS, Jeong JH, Shin S and Song SY: Megestrol acetate increases the proliferation, migration, and adipogenic differentiation of adipose-derived stem cells via glucocorticoid receptor. Stem Cells Transl Med 4: 789-799, 2015.

14. Nelson KA, Walsh D and Hussein M: A phase II study of low-dose megestrol acetate using twice-daily dosing for anorexia in nonhormonally dependent cancer. Am J Hosp Palliat Care 19: 206-210, 2002.

15. Votaw ML: Excessive sweating: Unusual side effect of megestrol acetate therapy. Tenn Med 90: 59, 1997.

16. Woo SM, Choi YK, Kim AJ, Yun YJ, Shin YC, Cho SG and Ko SG: Sip-jeon-dea-bo-tang, a traditional herbal medicine, ameliorates cisplatin-induced anorexia via the activation of JAK1/STAT3-mediated leptin and IL-6 production in the fat tissue of mice. Mol Med Rep 13: 2967-2972, 2016.

17. Choi YK, Jung KY, Woo SM, Yun YJ, Jun CY, Park JH, Shin YC, Cho SG and Ko SG: Effect of Sipjeondaebo-tang on cancer-induced anorexia and cachexia in CT-26 tumor-bearing mice. Mediators Inflamm 2014: 736563, 2014.

18. Ohno T, Yanai M, Ando H, Toyomasu Y, Ogawa A, Morita H, Ogata K, Mochiki E, Asao T and Kuwano H: Rikkunshito, a traditional Japanese medicine, suppresses cisplatin-induced anorexia in humans. Clin Exp Gastroenterol 4: 291-296, 2011.

19. Takeda H, Sadakane C, Hattori T, Katsurada T, Ohkawara T, Nagai K and Asaka M: Rikkunshito, an herbal medicine, suppresses cisplatin-induced anorexia in rats via 5-HT2 receptor antagonism. Gastroenterology 134: 2004-2013, 2008.

20. Song BK, Won JH and Kim S: Historical Medical Value of Donguibogam. J Pharmacopuncture 19: 16-20, 2016.

21. Zee-Cheng RK: Shi-quan-da-bu-tang (ten significant tonic decoction), SQT. A potent Chinese biological response modifier in cancer immunotherapy, potentiation and detoxification of anticancer drugs. Methods Find Exp Clin Pharmacol 14: 725-736, 1992.

22. Piao JH, Zhang L, Zhang H, Gao TH and Li XH: Experimental studies on antianimia effect of shengxuesu. Zhongguo Zhong Yao Za Zh 28: 544-547, 2003 (In Chinese).

23. Sun W, Meng K, Qi C, Yang X, Wang Y, Fan W, Yan Z, Zhao X and Liu J: Immune-enhancing activity of polysaccharides isolated from Atractylodis macrocephalae Koidz. Carbohydr Polym 126: 91-96, 2015
24. Lv Y, Feng X and Zhu B: Study on effect of Astragalus membranaceus injection on hematopoiesis in anemic mice with myelosuppression. Zhong Yao Cai 28: 791-793, 2005 (In Chinese).

25. Zhu X and Zhu B: Effect of Astragalus membranaceus injection on megakaryocyte hematopoiesis in anemic mice. Hua Xi Yi Ke Da Xue Xue Bao 32: 590-592, 2001 (In Chinese).

26. Auyeung KK, Han QB and Ko JK: Astragalus membranaceus: A review of its protection against inflammation and gastrointestinal cancers. Am J Chin Med 44: 1-22, 2016.

27. Shang X, Pan H, Li M, Miao X and Ding H: Lonicera japonica Thunb.: Ethnopharmacology, phytochemistry and pharmacology of an important traditional Chinese medicine. J Ethnopharmacol 138: 1-21, 2011.

28. Rasool S and Sharma B: Taraxacum officinale: A high value less known medicinal plant. Ann Plant Sci 3: 908-915, 2014

29. Kirba $\breve{g ~ S, ~ Z e n g i n ~} F$ and Kursat M: Antimicrobial activities of extracts of some plants. Pak J Bot 41: 2067-2070, 2009.

30. Fang X, Yu MM, Yuen WH, Zee SY and Chang RC: Immune modulatory effects of Prunella vulgaris L. On monocytes/macrophages. Int J Mol Med 16: 1109-1116, 2005.

31. FDA K: Safety MOFAD: Guidance on good manufacturing practices (GMP) for active pharmaceutical ingredients, 2015.

32. Organization WH: Annex 3 supplementary guidelines on good manufacturing practices for the manufacture of herbal medicines., pp85-106, 2006.

33. Damia G and D'Incalci M: Mechanisms of resistance to alkylating agents. Cytotechnology 27: 165-173, 1998.

34. Malhotra V and Perry MC: Classical chemotherapy: Mechanisms, toxicities and the therapeutic window. Cancer Biol Ther 2 (4 Suppl 1): S2-S4, 2003.

35. Lee CS, Ryan EJ and Doherty GA: Gastro-intestinal toxicity of chemotherapeutics in colorectal cancer: The role of inflammation. World J Gastroenterol 20: 3751-3761, 2014.

36. Ohnishi S and Takeda H: Herbal medicines for the treatment of cancer chemotherapy-induced side effects. Front Pharmacol 6: 14, 2015.

37. Takeda H, Muto S, Nakagawa K, Ohnishi S and Asaka M: Rikkunshito and ghrelin secretion. Curr Pharm Des 18: 4827-4838, 2012

38. Dixit VD, Schaffer EM, Pyle RS, Collins GD, Sakthivel SK, Palaniappan R, Lillard JW Jr and Taub DD: Ghrelin inhibits leptin- and activation-induced proinflammatory cytokine expression by human monocytes and T cells. J Clin Invest 114: 57-66, 2004.

39. Zhang F, Chen Y, Heiman M and Dimarchi R: Leptin: Structure, function and biology. Vitam Horm 71: 345-372, 2005.

40. Shirazi R, Palsdottir V, Collander J, Anesten F, Vogel H, Langlet F, Jaschke A, Schürmann A, Prévot V, Shao R, et al: Glucagon-like peptide 1 receptor induced suppression of food intake, and body weight is mediated by central IL-1 and IL- 6 . Proc Natl Acad Sci USA 110: 16199-16204, 2013.

41. Buettner C, Pocai A, Muse ED, Etgen AM, Myers MG Jr and Rossetti L: Critical role of STAT3 in leptin's metabolic actions. Cell Metab 4: 49-60, 2006.

42. Engineer DR and Garcia JM: Leptin in anorexia and cachexia syndrome. Int J Pept 2012: 287457, 2012.

43. Suprasert P, Aue-Aungkul A and Pautad N: Lack of Relationship of Egg white intake with occurrence of leukopenia in gynecologic cancer patients during chemotherapy. Asian Pac J Cancer Prev 17: 1265-1267, 2016.

44. Rodgers GM III, BeckerPS, BennettCL, CellaD, Chanan-Khan A, Chesney C, Cleeland C, Coccia PF, Djulbegovic B, Garst JL, et al: Cancer- and chemotherapy-induced anemia. J Natl Compr Canc Netw 6: 536-564, 2008

45. Munoz-Langa J, De Castro J, Gasco P, et al:: Chemotherapyassociated anemia in patients with lung cancer: An epidemiological, retrospective and multicenter study. Future Oncol 11: 1665-1674. 